\title{
Business Ethics of Pakistanis in Islamabad and Lahore: Do Age, Gender and Data Collection Processes Make a Difference?
}

\author{
Dr. Bahaudin G. Mujtaba \\ (Corresponding Author) \\ The H. Wayne Huizenga School of Business and Entrepreneurship \\ Nova Southeastern University \\ Fort Lauderdale, Florida, 33314. USA. \\ Email: mujtaba@nova.edu; Phone: (954) 262-5045 \\ Dr Arif Sikander \\ Murdoch Business School, MBS2 Room 8; Murdoch University \\ 90 South Street \\ Murdoch, Perth, Western Australia 6150 \\ Phone: 08-9360-6030; Email: A.Sikander@murdoch.edu.au \\ Dr. Naveed Akhtar, Assistant Professor \\ Department of Management Sciences, \\ National University of Modern Languages, Islamabad, Pakistan \\ Email: naveedakhtarbaloch@yahoo.co.uk \\ Dr. Talat Afza \\ Head of Academics and Research \\ COMSATS Institute of Information Technology \\ Lahore, Pakistan \\ Email: talatafza@ ciitlahore.edu.pk; Phone: (09242)-35321092
}

Accepted: June 5, 2012 Published: June 19, 2012

Doi:10.5296/ijld.v2i3.1972 URL: http://dx.doi.org/10.5296/ijld.v2i3.1972 
Abstract

Pakistan is an emerging economy and a modernizing workplace. This research surveyed 318 citizens, managers, and employees in Lahore and Islamabad to measure their Personal Business Ethics Scores (PBES) based on age and gender, as well as to see if face-to-face and online data collection processes make a difference in their level of ethical maturity. Furthermore, this study contributes to the theory of moral development. The results suggest that age is a significant factor in moral development as it leads to higher scores in moral maturity. Gender is not a factor in the ethical maturity scores of these respondents. Kohlberg's moral development theory regarding ethical maturity is supported since those who were older do have higher business ethics scores. Furthermore, significant differences were found based on the data collection process. These results can be helpful for human resources managers and expatriates who work in these cities with local professionals. Suggestions and implications are discussed.

Key words: Business Ethics, Ethical Maturity, Gender, Age, Pakistan, and Moral Development.

\section{Introduction}

An ethical climate is crucial for business and governance. The creation of this ethical climate requires the development of a culture where each individual is driven to behave according to the prevailing and driving norms and values standardized by a society to enforce high moral standards. Pakistan is a very religious and spiritual country, where people place a strong emphasis on justice, harmony, and generosity in the workplace (Ali and Amirshahi, 2002). From a spiritual perspective, faith and belief in a higher power tends to lead to greater levels of morality and, thus, ethical behaviors (Barham, Younies and Muhamad, 2009). Moral development is the growth of a person's ability to distinguish right from wrong, and it refers to progressive and continuous changes from the beginning of life until the end (Mujtaba, Tajaddini, and Chen, 2011). Moral development occurs through the process of learning and socialization during one's life, religious practices, education, and general growing up (Mujtaba, Cavico, McCartney, and DiPaolo, 2009). A key research question might be to see which demographic variables make a difference in the ethical decision making of Pakistani respondents. Building on the theory of moral development, the purpose of this study is to determine whether age and gender are related to ethical decision making with the adult working population in Pakistan. Consequently, this current research is designed to explore and assess the Personal Business Ethics Scores (PBES) of Pakistani respondents in two major cities using face-to-face and online data collection processes.

Ram, Khoso, Jamali, and Shaikh (2009) view ethics mainly in the context of the individual and define it as an "individual's personals belief about whether a behaviour, action, or decision is right or wrong." They further narrate "moral obligation" as the main focus of ethics. Ram et al., (2009) stress that study of good and bad human behaviour or conduct in terms of values, beliefs and actions is the subject matter of ethics. Contrary to logic that provides a standard through which one's actions or statements is judged as true or false, ethics 
provides standards that help people to evelaute their actions in respect to right or wrong. Combining it with the corporate world, business ethics constitutes the study of moral problems faced by organizational members during their course of business.

Butt, Bhotto and Siddiqui (2011) mention a study that was conducted with the perspective of consumer's ethical beliefs which explored that the ethical judgment of the consumers was the outcome of three main factors: 1) consumer's perception of the activity on whether it is legal or illegal; 2) whether the seller or the buyer is at fault or not; and 3) whether the seller will be harmed or not. According to Butt, Bhotto and Siddiqui (2011), the results are consistent with other studies which identified three similar factors in the area of business ethics.

Another study which appears to be a significant contribution within the context of business ethics in Pakistan is aimed at identifying the relationship of organizational ethics and job satisfaction. According to Ahmed, Shad, Mumtaz, and Tanveer (2012), this study surveyed 230 bank employees (public \& private). The employees recognized three ethical climate types including egoistic ethical climate, benevolent climate for ethics, and principled ethical climate. With relation to egoistic climate of ethics, the study found a negative relationship with job satisfaction, whereas conducive and cooperative business atmosphere is gained through benevolent and principled ethical climate. Lastly, the study also found a positive relationship between benevolent climate for ethics and job satisfaction (Ahmed, Shad, Mumtaz \& Tanveer, 2012).

One of the studies to see the ethical consideration in private banks in Pakistan was conducted in 2009. The objectives of the study as mentioned by Ram, Khoso, Jamali, and Shaikh (2009) were: examining the qualities of a successful banker and linking it with moral values, and identification of ethical issues in assessment of loan application, maintenance of secrecy of account holder, realization of dues from customers. The research findings based on 500 respondents (customers) suggest that ethical consideration in terms of caring for the customers is not an agenda for private commercial banks in Pakistan. The banking staff attitudes were found unfriendly with customers. The study also identified many unethical behaviors such as influencing the customers in hopes of diverting the loans in other purposes, delaying sanctioning loans, sending the legal notice after due date, and/or fixing up payment schedules without necessarily considering the surplus generation capacity of the borrower (Ram, Khoso, Jamali, \& Shaikh, 2009).

Based on the above findings of different research on the topic of business ethics in the context of Pakistan, it is concluded that the subject matter is indeed not much explored in terms of depth and breath. Very few studies are broad in nature; hence no general thought process is attained as to what people think regarding business ethics. Therefore, it is suggested that "business ethics" should be looked into at the basic understanding level and then gradually relating into more complex relationships with other management constructs.

\section{The Cultural Contexts of Lahore and Islamabad in Pakistan}

Pakistan is a country located in South Asia and Southwest Asia, Middle East and converges with Central Asia and the Middle East. It has a 1,046 kilometer (650 miles) coastline along the Arabian Sea and Gulf of Oman in the south, and is bordered by Afghanistan and Iran 
in the west, India in the east and China in the far northeast. Pakistan is the sixth most populous country in the world and has the second largest Muslim population in the world after Indonesia. It has a population of over 170 million citizens and growing fast (Afza, Mujtaba, and Habib, 2011). Pakistani culture is actually a part of the contemporary Islamic civilization which draws its values and traditions from Islam and rich Islamic history. Pakistani culture is rich in the literatures of Urdu, Punjabi, Sindhi, Pashtu, Baruhi, Baluchi, and Kashmiri languages. Pakistani society is dominated by male members. Each family is headed by the senior most male member who is responsible for arranging the "bread and butter" of the family. Islam is practiced by the majority of Pakistanis and governs their personal, political, economic, and legal lives. The extended family is the basis of the social structure and individual identity. Pakistan is a hierarchical society where people are respected because of their age and position.

Islamabad and Lahore are the two main cities of the province of Punjab, the former being the country's capital and the later provincial capital. Lahore is the second largest city in Pakistan with a population of roughly 8.5 million. The traditional capital of Punjab for a thousand years, it had been the cultural center of Northern India extending from Peshawar to New Delhi. Lahore's culture is unique which sometimes is referred to as the cultural capital or the heart of Pakistan. The culture of Lahore is a manifestation of the lifestyles, festivals, literature, music, language, politics, cuisine, and socio-economic conditions of its people. Today, Lahore can be best described as a city that is just so wonderful, so very fabulous, that every nook and corner of the city speaks of certain vibrancies, certain zeal, and a fresh spirit for life which cannot be found anywhere else in the world. Regarding similarities to other Mughal cities...the average Lahori is that same old Mughal prince of bygone ages, one only has to get to know him. There is an old saying, that in every Lahori, there is a Mughal prince. It is rare that foreigners get a glimpse of the Punjab's dominant form of Islam: Sufism. Sufi adherents often gather together on Thursday nights seeking spiritual enlightenment, or merely a good time, through traditional qawwali singing.

Being a capital, mainly Islamabad is famous for government offices, Parliament House, diplomatic enclaves and foreign embassies. Majority of the people living in Islamabad are government employees. They do have a lively social life in Islamabad but not as much as other cities. On public holidays and weekends people go to their hometowns to see their families/relatives. During last ten years this trend has been changed since many restaurants, fast food chains, and shopping centers have been opened in the city. These changes have naturally improved the nightlife and the city has become livelier for nighttime entertainment.

Islamabad is the first planned city of Pakistan and is a rather modern, clean and well organised city as compared to other cities of Pakistan. For administrative purposes the new city of Islamabad is divided into different sectors and zones. There are eight zones and several different sectors. Each sector in Islamabad is identified by the English alphabet letter D to I and a number 5 through 12. Each sector in Islamabad has an area of $2 \times 2$ kilometres and further subdivided into 4 subsectors. Each subsector in Islamabad has its own market and children park. When compared to the other cities of Pakistan, Islamabad is a relatively new city. Being the capital of Pakistan, Islamabad has turned into the most green, beautiful and fast growing metropolitan city of the South Asia. Daman e Koh Park, the huge marble Shah Faisal Mosque, incised gardens of Islamabad's Shakar Parian Hills, and the fascinating Heritage Museum at 
Lok versa (cultural complex) are some highlighted spots of this modern city of Islamabad. Blue Area is the central business district and commercial centre of Islamabad running along the length of Jinnah Avenue. Its eastern end runs into Parliament Road, where the majority of government buildings are located. Being the capital of the country, Islamabad has a modern culture that is at synch with other internationalized cities.

\section{Business Ethics and Social Responsibility}

Business is a network of processes and transactions to create wealth and value. Normative ethics - those systems that guide individuals in the difference between right and wrong - are applied to particular decisions and actions that yield a desired and ideally positive outcome (Boatright, 2007; DeGeorge, 2006). If loyalty is the ultimate prize due to the value that it carries presently and implies for the future, then the "social responsibility" of the organization is to attract and retain the people with the skills and abilities that the organization needs to build value and sustain loyalty (Collins, 2001). In this context, social responsibility is the core objective of the manager to employ capable, confident people in positions for which they are qualified and from which they can earn full and fair compensation (White, 2010). Yet, the composite of skills and abilities of the people in the organization, their cares and concerns, are dynamic and need a structure in which to manage their own uncertainties and respond to their own "strategic" (self-interest) issues. They need a mechanism beyond a bi-weekly paycheck or a trade-union card to feel a part of something bigger and major in their lives (White, 2010, p. 5).

In recent years, there have been clear signs that the orthodox view of business is breaking down due to increased concerns for factors like global warming, corporate scandals like Enron, conduct of businesses in the arms trade, and the huge executive earnings (Hall, 2007, p. 5). Most business professionals are confused on the meanings assigned to the most commonly used terms, such as business ethics and social responsibility, which can make the task of managers difficult if they do not understand what these imply. Ethics deal with the right and wrong and a bit further than the legal minimum. Social responsibility entails caring about those who will be affected by the corporate decisions (Cheney, 2006, p. 15).

Most companies do not distinguish between business ethics and corporate social responsibility when it comes to determining what it means for a company to be ethical. These tend to be located in separate departments having different lines of authority (Berenbeim, 2006, p. 501). There is a need to integrate them into a single model of an ethical company. Modern companies must have safeguards that minimize the lapses of ethical occurrences and at the same time require policies that are deemed to be socially responsible (Berenbeim, p. 501).

Ethics deal with the strength of the relationship between what an organization and an individual believes to be correct and moral and what available sources of guidance suggest is morally correct. Moreover, ethics is general concerned with the strength of the relationship between how one behaves and what one believes. Ethics is catalyzing managers to take socially responsible actions. Business ethics is concerned with the capacity to reflect values in the decision-making process, to point how these values and decisions affect stakeholder groups, and to establish how managers are able to use these observations in day-to-day enterprise management (Chitakornkijsil, 2011, p. 46). Cordiero (2003) asserts the development of ethical 
behavior in managers ought to be grounded in their development as leaders, since ethics is not something a leader or entrepreneur does, but rather it is something that a person is because of his/her beliefs, behaviors and overall character.

Social responsibility refers to the enforced, implied, or felt obligation of managers, acting in their official capacity, to protect and serve the interests of groups other than themselves. A corporation's approach to social responsibility means corporate executives to be making decisions that closely meet the expectations of society (Chitakornkijsil, 2011, p. 46). The American Management Association and the Committee for Economic Development, encourage managers and companies to be involved in socially responsible activities, such as the following:

1) Reduction of environmental pollution.

2) Financial and leadership aid for urban renewal.

3) A safe working environment.

4) Financial and managerial aid aimed at improving medical care and health.

5) Financial assistance for education.

6) Promotion and better jobs opportunities for women and minorities (Chitakornkijsil, 2011, p. 46).

Social responsibility can differ by the industry as well as companies within an industry and address the following areas: product quality, product safety, environment, energy, business behavior, human resource and societal impact. Thus, it talks about all positive activities compared to dealing with moral conflicts under ethics (Fulop et al., 1999, p. 5). Both ethics and social responsibility play a vital role in the economic development and business environment in the industry. In a study carried out by Fulop et al., (1999, p. 29), in Hungary managers of large and small companies viewed social responsibility differently. However, their views on ethics were similar.

Organizations and society at large recognize that ethically and socially responsible behavior plays a crucial role in good business practices. This realization has led employers to expect and demand that business schools facilitate the training of students in ethics and social responsibility (Nicholson and DeMoss, 2009, p. 213). Because corporations and consumers are increasingly reassessing the central role of corporate social responsibility, business education can no longer keep this issue on the periphery (Nicholson and DeMoss, 2009, p. 217).

The beginning of business ethics as an academic area of pursuit came about from the work of scholars at American Catholic universities. They developed business ethics by applying ethical theory to business studies, and the study of business ethics was born (Freeman, Stewart \& Moriarty, 2009). Trevino and Nelson (2010) argue that given the ethical debacles of the past three decades, future business professionals must have a better understanding of business ethics and be better prepared to manage and lead effectively and ethically.

A study carried out by Diss and Jennifer (2011) found that there was not a significant difference in the opinions of graduate business students and non-business graduate students when it came to ethics. Both groups of students surveyed were found to have similar answers. Also there was no significant difference in the business graduate and non-business graduate students' social responsibility scores. It was also found that business graduate students' age 
was a statistically significant factor for business students in relation to their business ethics score. Business students scoring higher on overall social responsibility means that the courses in business ethics and industry practices increased students' understanding of what is expected from them as business professionals and what is expected from the companies for which they will work. Business students' gender and ethnicity was not statistically significant factors in their social responsibility judgment.

The need for established ethical frameworks and practices in business communities has never been greater. Corporate social responsibility (CSR) has also risen up the corporate agenda, as society is increasingly demanding that corporations should act responsibly (Cornelius et al., 2007). A core part of CSR is ethical behavior. The definition of CSR, developed by the World Business Council for Sustainable Development (Moir, 2001) reflects an alternative, multi-stakeholder, implicitly multidisciplinary and more proactive view of CSR that is gaining popularity: CSR is the continuing commitment by business to behave ethically and contribute to economic developments while improving the quality of life of the workforce and their families as well as the local community and society at large. CSR can be assessed by four distinct components, namely Social Inclusion (SI); Ethical Responsibility (ER); Social Responsibility (SR) and Engagement in Society (ES) (Cornelius et al., 2007, p. 124). In the current climate where CSR and ethics are firmly in place on the socio-political and business agendas, the concept of SI can be seen largely as a manifestation of CSR and ethics at this point in time. The implications are that organizations will be engaging more actively in CSR and ethics programs to ensure that they not only comply with regulations, but also that their CI is one which is favorable to its stakeholders and commercial milieu (Cornelius et al., 2007, p. 132).

Homann (2002) states that in the age of globalization, moral foundations should be based on advantages and incentives, and that ethics is not about following rules, but about developing them, i.e. not about just following rules but setting the rules of the game. Poverty is undoubtedly a key question for global ethics and justice, because no other moral deficit withholds fundamental human rights and dignity from so many people (Bardy et al., 2012, p. 270). As such results of ethics studies in one country may not be transferable to other. It would be good to compare apples with apples. As such, this study compares respondents from two different cities of the same country and culture.

Hypothesis I -Pakistanis in Islamabad will have Personal Business Ethics Scores (PBES) that are similar to those from Lahore.

Since today's professional are busier than ever before and survey completion takes time, many individuals do not complete ethics related surveys. Furthermore, ethics deals with honesty and some respondents might feel uncomfortable answering questions in a face-to-face format (Mujtaba, 1997). In Pakistan, the best way to increase the response rate is to personally interview people and document their answers or to give them time to complete the responses while the researcher is waiting for them. This time pressure might influence the responses. Perhaps people might be more honest in their responses if they are given the option of completing the survey on their own time through an online medium. Consequently, the survey 
completion process may have an influence on the ratings of ethical dilemmas. To find out more, the study for this article focused on the following hypothesis:

Hypothesis II -Pakistanis who complete the survey through face-to-face format will have Personal Business Ethics Scores that are similar to those who complete it online.

Age is important since it is associated with experience and wisdom. As such, a person's age is expected to relate to that person's moral maturity. It is generally agreed that older individuals tend to be more ethical or possess more strict views of moral issues than younger ones. As individuals progress through the experience of life, they should develop higher stages of moral cognition. According to Huang (2006), students in the 40-plus age group are the most ethical. The findings are consistent with other studies which state that older students exhibit more ethical inclinations. Some studies conclude that younger respondents tend to be less ethical than older people (Huang, 2006). Arial (2005) found that the age groups 40-49 and 50-59 had higher DIT moral maturity scores than the other groups. Chavez (2003) indicated that banking employees who are less than 30 years of age tend to have lower moral maturity scores than banking employees who are 30 years of age and older (Chavez, 2003, p. 58). Hyppolite (2003) concluded that the average score for moral maturity of older participants was higher than the one for younger respondents. As one matures in age, his or her average moral maturity score is likely to increase. This research indicated age was a predictor of individual maturity level (Hyppolite, 2003, p. 139). Cannon's results revealed that there is empirical support for age as a predictor of moral development in a meta-analysis of multidisciplinary ethics studies (Cannon 2001, p. 195). Kohlberg's Cognitive Moral Development theory posits that as a person increases in age in a given culture, his or her capability and level of moral reasoning should progressively increase too. Therefore, the study for this article focused on the following hypothesis related to age and different cities in Pakistan:

Hypothesis III -Younger Pakistanis will have Personal Business Ethics Scores (PBES) that is similar to those who are older.

Many claim that gender is a significant factor in ethical maturity and ethical decision making (Borkowski \& Ugras 1998; Forte 2004; Jones \& Hiltebeitel 1995; Stedham,Yamamura \& Beekun 2007; White 1999). Other researchers such as Derry (1989) have found that gender is unlikely to be a significant factor in ethical decision making. An effective and strong organizational culture often leads to an alignment between the manager's decisions and the organization's core values (Cable \& Parsons, 2001); consequently, gender may not make any significant difference. To find out more, the study for this article focused on the following hypothesis:

Hypothesis IV -Pakistani males will have Personal Business Ethics Scores that are similar to females.

\section{Research Methodology and Analysis}

This study uses Clark and Clark's (1966) instrument to compare the results of Personal Business Ethics Scores (PBES) of respondents in Pakistan. The comparisons are based on age, 
gender and data collection techniques. The research question to be answered is whether age, gender, and data collection processes affect the moral development of individuals in Pakistan.

The self-administered questionnaires used in this study offer anonymity which is important when conducting ethics research. The English version of the survey was translated into Urdu and then it was given to three university professors who spoke both languages fluently for checking the accuracy of the translated survey. Then a fifth professor back-translated the Urdu survey into English to see if the meaning had stated the same. The authors and their colleagues agreed that the meaning of the survey had not changed in the Urdu translated version.

\section{Population Demographics}

The PBES surveys were sent to Pakistanis in the capital city of Islamabad as well as in Lahore and its surrounding areas. In the traditional face-to-face format, 500 questionnaires were sent to the candidates. The convenience sample was obtained through educational organizations, businesses and entrepreneurs, which included both private and public sector institutions. A paragraph explaining the purpose of this research and guaranteeing total confidentiality was included with each survey. Since some people do not like to complete surveys in Pakistan as they may not feel comfortable with the content or they may not trust the source (Mujtaba and Afza, 2011), two faculty members were assigned to personally interview candidates who volunteered for the survey and recorded their answers. As such, about $50 \%$ of the surveys come from workers and managers who agreed to be personally interviewed by the assigned interviewers. Out of the total surveys distributed to respondents in a traditional format in and around Lahore areas, a total of 231 usable surveys, comprising a response rate of $46 \%$, were used for analysis in this study.

In the online format, 500 working adult respondents living Islamabad were sent an online survey link which was available only in the English language. Since Pakistanis study all of their courses in English starting from primary school, language is assumed not to be an issue. Through the online email, the respondents were encouraged to complete the survey within a three-week period, but were given over three months in case they choose to complete it at a later date. A total of 87 online respondents completed the survey which makes a response rate of about $18 \%$. The total number of respondents from the online survey as well as the face-to-fact data collection processes in this study is 318 ( $31 \%$ response rate).

The questionnaire used consists of eleven questions which represent the Personal Business Ethics Scores (PBES). The PBES represents a score between 11, indicating low personal business ethics, to 55, indicating very high personal business ethics. An analysis at the $\mathrm{p}<.05$ level of significance is used to determine if there are differences in the responses of people based on age, gender, and data collection medium.

\section{Hypotheses Testing}

The total personal business ethics score of the 318 Pakistani respondents are 37.597 (standard deviation of 8.668) out of a possible scores of 55. The higher the score, the higher the presumed level of ethical maturity and intolerance for inappropriate business dealings. 
The first hypothesis which states "Pakistanis in Islamabad will have Personal Business Ethics Scores (PBES) that are similar to those from Lahore" cannot be accepted since respondents from Lahore appear to have a significantly higher score (see Table 1). Similarly, the second hypothesis which states that "Pakistanis who complete the survey through face-to-face format will have Personal Business Ethics Scores that are similar to those who complete it online" cannot be accepted since respondents who completed the surveys through face-to-face (traditional) format appear to have a significantly higher ethical maturity score.

\section{Table 1 - PBES Scores: Islamabad vs. Lahore}

\begin{tabular}{l|l|l|l}
\begin{tabular}{l|l} 
Group (Data \\
Collection Process)
\end{tabular} & $\begin{array}{l}\text { Sample } \\
\text { Size }\end{array}$ & Mean & $\begin{array}{l}\text { Standard } \\
\text { Deviation }\end{array}$ \\
\hline Islamabad (Online) & 87 & 34.977 & 7.803 \\
Lahore & 231 & 38.58 & 8.787 \\
$($ Face-to-Face $)$ & & & \\
\hline \multicolumn{3}{l}{$t=-3.36 ; p=0.000881$}
\end{tabular}

Since the culture is the same and both people-groups are all from the same religious backgrounds, then we can assume that the scores are higher simply due to the fact that two different data collections techniques were used. Respondents from Lahore who completed the hard copy surveys in face-to-face formats have a significantly higher level of ethical maturity.

Table 2 - Younger and Older PBES Scores

\begin{tabular}{l|l|l|l} 
Position & $\begin{array}{l}\text { Sample } \\
\text { Size }\end{array}$ & Mean & $\begin{array}{l}\text { Standard } \\
\text { Deviation }\end{array}$ \\
\hline Younger & 138 & 35.84 & 8.672 \\
Older $(>26)$ & 180 & 38.944 & 8.444 \\
\hline \multicolumn{3}{c}{$t=-3.21 ; p<0.00$}
\end{tabular}

The hypothesis stating that Pakistanis who are younger (25 years of age or younger) will have Personal Business Ethics Scores (PBES) that are similar to those who are older (26 years of age or older) cannot be supported. Table 2 shows the results of the t-test based on age. The PBES mean of older individuals is significantly higher than younger respondents. So there are statistically significant differences in personal business ethics scores of younger and older Pakistanis. Older Pakistanis have demonstrated a higher level of ethical maturity than those who are less than 25 years of age.

The last hypothesis states that male Pakistanis will have Personal Business Ethics Scores that are equivalent to females and it could not be rejected. The analysis result (Table 3) shows that there were no significant differences in personal business ethics scores of males and females in Pakistan. 
Table 3 - Males vs. Female PBES Scores

\begin{tabular}{l|l|l|l} 
Position & $\begin{array}{l}\text { Sampl } \\
\text { e Size }\end{array}$ & $\begin{array}{l}\text { Mea } \\
\mathrm{n}\end{array}$ & $\begin{array}{l}\text { Standard } \\
\text { Deviation }\end{array}$ \\
\hline Males & 219 & $\begin{array}{l}37.7 \\
4\end{array}$ & 8.58 \\
& & $\begin{array}{l}37.2 \\
73\end{array}$ & 8.888 \\
Females & 99 & \multicolumn{3}{c}{$0.45 ; p=0.6557$}
\end{tabular}

This study concludes that age is a factor in the moral development of respondents in Pakistan. Furthermore, this study also demonstrated that respondents in Lahore appear to demonstrate less tolerance for unethical behaviors in business than their colleagues in Islamabad. Gender did not demonstrate any significant differences. Finally, those who completed the survey online, which was offered only in English, have significantly lower personal business ethics scores than those who completed the study through face-to-face format.

\section{Discussion, Implications and Limitations}

Foreign managers and expatriate employees who work in Pakistan must understand the local culture and customs of people in order to build an effective long-term work relationship with them. As such, reflections on these results can be helpful for managers and expatriate employees who work with local professionals in Islamabad and Lahore provinces of Pakistan. Accordingly, this section provides a brief reflective discussion on the results. This study focused on respondents from Pakistan to determine their commitment level to personal integrity and honesty in business dealings based on age, gender, city (district), and data collection modality. In this study, using the survey instrument with the Pakistani population, gender did not produce any statistically significant results. However, it should be mentioned that the older group and those living in Lahore did have higher average business ethics scores.

The statistical analysis results showing differences in the score of two cities, Islamabad and Lahore, apparently signify the impact of data collection methods applied. It is observed during the different studies conducted in Pakistan that the questionnaire distributed in hard copy format allows the respondent more time and apprehension of the questionnaires because they can fill the response in their convenience without feeling any pressure; whereas the online survey puts pressure of filling the response and responding within a "perceived" limited time period. It could also be argued that respondents in Lahore have been exposed to a deep rooted sub-culture compared to Islamabad, and perhaps value business ethics more.

It is noteworthy to mention that in another hypothesis there is no difference in scores of males and females. The statistically insignificant difference of gender scores further substantiates the arguments that the statistical mean difference of respondents of two cities, Islamabad and Lahore, might be due to different data collection techniques used. Moreover, it 
appears that administering the PBES questionnaire in Urdu might have caused the difference in statistical inferences. Urdu being local language might have increased the apprehension level of respondents effecting statistics. As such, future researchers should offer the survey in similar formats in all regions.

Statistical difference on the basis of age appears to be the result of maturity of behaviors which develop over time because of on-the-job learning and with the interaction among society members. People generally change their jobs during the 22-26 years of age and get settled while nearing their thirties. It is generally observed in Pakistan that employees join their job and keep improving their educational qualifications in order to eventually switch over to other suitable jobs. Such trends certainly do not let employees establish loyalty with their employers. Upon achieving a more mature age and a stable career, one's socialization can further improve his/her thinking pattern and cultural values and norms which result in higher level of maturity in business.

Statistical results underpin the necessity of business ethics goals or corporate ethics statements which should be communicated to each employee. A culture of high moral values and norms and business ethics should be inculcated in the culture of each organization. Parameters of the high moral culture should be constructed, communicated, nurtured, and evaluated. The strategies and practices should be rooted through top management's day-to-day actions and behaviors. Therefore, it is suggested that high ethical standards should be practiced and encouraged by senior executives.

For future research, researchers can conduct similar studies in other areas of the country to determine if there are statistical differences in PBES scores based on modality, age, gender, and other demographic variables such as educational background, career fields, management experience, government experience, and ethics training and education. It would be also interesting to compare scores of cities from several different provinces to observe the influence of provincial cultures on business ethics. Similarly, studies can be conducted in other countries to see the reliability and validity of the scores. A comparative study of western societies and developing countries will reveal further differentiating dimensions of business ethics.

The methodology was self-limiting as in one city (Lahore) the questionnaire was administered in Urdu, whereas in other (Islamabad) it was in English. Analysis was conducted on the basis of age, gender, and city. Future studies could also be conducted on the basis of experience, nature of appointment, interaction with public, nature of business, type of organization (public or private).

\section{Conclusion}

This research was designed to compare the Personal Business Ethics Scores (PBES) of respondents based on age, gender, city (district), and data collection process in Pakistan. Age is definitely a factor in the moral development and, thus, ethical maturity level of respondents in Pakistan. Since age is often moderated by experience, education and learning, the establishment of a comprehensive training plan for the transmission of ethical values to all working professionals might be a good start in creation and development of a more ethical business environment. Gender was not a factor in the ethical maturity of respondents as males and females has similar business ethics scores. 
The medium of data collection process was a factor and those who completed the responses by hand through a face-to-face format did demonstrate a higher level of ethical maturity. Perhaps the face-to-face format of communication and interaction is a much richer and better medium for accurate and honest responses. On the other side, it is also possible that people who completed the surveys online are likely to more quickly form their decisions without thoroughly thinking about their responses or having the opportunity to re-read their answers. As such, since online communication is becoming more common today, this is an area for further research consideration as it can have practical implications for education and development of employees.

\section{REFERENCES}

Ahmed, B, Shad, I., Mumtaz, R., \& Tanveer, Z. (2012). Organizational ethics and job satisfaction: Evidence from Pakistan. African Journal of Business Management, 6(8), 2966-2973.

Ali, A. J. and Amirshahi, M. (2002). The Iranian manager: Work values and orientations. Journal of Business Ethics, 40, 133-143.

Ariail, D. L. (2005). Personal Values, Moral Development, and Their Relationship: A Study of Certified Public Accountants. Doctoral Dissertation, Nova Southeastern University.

Bardy, Roland, Drew, Stephen, and Kennedy, Tumenta F. (2012). Foreign Investment and Ethics: How to Contribute to Social Responsibility by Doing Business in Less-Developed Countries. Journal of Business Ethics, 106(3), 267-282.

Barham, B., Younies, H. and Muhamad, R. (2009). Religiosity and work stress coping behavior of Muslim employees. Education, Business and Society: Contemporary Middle Eastern Issues, 2(2), 123-137.

Berenbeim, Ronald E. (2006). Business Ethics and Corporate Social Responsibility. Vital Speeches of the Day, 72(16/17), 501-504.

Boatright, J. R. (2007). Ethics and the conduct of business ( $5^{\text {th }}$ ed.). Upper Saddle River, NJ: Pearson Prentice Hall.

Borkowski, S., \& Ugras, Y. J. (1998). Business students and ethics: A meta-analysis. Journal of Business Ethics, 17, 1117-1127.

Butt, F., Bhutto, N. A., \& Siddiqui, N. A. (2011). Investigating the Ethical Beliefs of Pakistani Consumers: An exploratory Approach. International Review of Business Research Papers, 7(1), 350-263. 
Cable, D. M. \& Parsons, C. K. (2001). Socialization tactics and person-organization fit. Personnel Psychology, 54, 1-23.

Cannon, C. (2001). Does Education Increase Moral Development? A re-examination of the Moral Reasoning Abilities of Working Adult Learners. Doctoral Dissertation, Nova Southeastern University.

Cavico, F. J. and Mujtaba, B. G. (2009). Business Ethics: The Moral Foundation of Leadership, Management, and Entrepreneurship, $2^{\text {nd }}$ edition. Pearson Custom Publications: Boston.

Chavez, J. (2003). Morality and Moral Reasoning in the Banking Industry: An Ethical and Cognitive Moral Development Examination. Doctoral Dissertation, Nova Southeastern University.

Cheney, Tim D.(2006). A Decision Making Model To Enhance Corporate Ethics / Business Ethics / Social Responsibility. Business Renaissance Quarterly, 1(3), 15-20.

Cherry, J., Lee, M. and Chien, C. S. (2003). A Cross-Cultural Application of a Theoretical Model of Business Ethics: Bridging the Gap between Theory and Data. Journal of Business Ethics 44(4), 359-376.

Chitakornkijsil, Pranee.(2011). Global perspective of business ethics and social responsibility. International Journal of Organizational Innovation, 4(1), 45-58.

Clark, K. (2008). Taking a bite out of cheating, with the help of technology. U.S. News and World Report, October 13 / October 20, pp. 74-76.

Clark, J. W., \& Clark, S. J. (1966). Religion and moral standards of American businessmen. Cincinnati: Southwestern Publishing Co.

Collins, J.C. (2001). Good to great: Why some companies make the leap and other don't. New York: HarperCollins.

Cordiero, W. P. (2003). The Only Solution to the Decline in Business Ethics: Ethical Managers, Teaching Business Ethics, 7(3), 265-277.

Cornelius, Nelarine, Wallace, James, and Tassabehji, Rana (2007) An analysis of corporate social responsibility, corporate identity and ethics teaching in business schools. Journal of Business Ethics, 76(1), 117-135.

Crary, D. (2008). Students lie, cheat, steal, but say they're good. Website: http://www.foxnews.com, accessed October 3, 2010. 
DeGeorge, R. (2006). Business ethics. (6 ${ }^{\text {th }}$ ed.) Upper Saddle River, NJ: Pearson Prentice Hall.

Derry, R. (1989). An empirical study of moral reasoning among managers. Journal of Business Ethics, 8, 855-862.

Desplaces, D. E., Melchar, D. E., Beauvais, L. L. and Bosco, S. M. (2007). The Impact of Business Education on Moral Judgment Competency: An Empirical Study. Journal of Business Ethics, 74(1), 73-87.

Diss. Ninneman\& Jennifer K. (2011).Business ethics and social responsibility: Comparing business and non-business graduate students. Capella University. 3473130.

Evans, S. P. K. (2004). A Study of Cognitive Moral Development Theory and Moral Maturity of African-American Business Professionals. Doctoral Dissertation, Nova Southeastern University.

Freeman, R.E., Stewart, L. \& Moriarty, B. (2009).Teaching business ethics in the age of Madoff. Retrieved September 6, 2010, from: http://www.changemag.org/Archives/ Back\%20Issues/November-December\%202009/full-teaching-business-ethics.html.

Freeman, W. J. (2007). Moral Maturity and the Knowledge Management Firm. Doctoral Dissertation, Nova Southeastern University.

Forte, A. (2004). Antecedents of Managers moral reasoning. Journal of Business Ethics, 51(4), 315-347.

Fulop, Gyula, Hisrich, Robert D. and Szegedi, Krisztina.(1999). Business ethics and social responsibility in transition economies. The Journal of Management Development, 19(1), 5-31.

Fryxell, G. and Lo, C. W. H. (2001). Organizational membership environmental ethics: A comparison of managers in state-owned firms, collectives, private firms and joint ventures in China. World Development, 29(11), 1941-1956.

Galla, D. (2006). Moral Reasoning of Finance and Accounting Professionals: An Ethical and Cognitive Moral Development Examination. Doctoral Dissertation, Nova Southeastern University.

Gao, L. (2004). Deficiency of Honesty from Cheat of College Students in a Test. Journal of Bingtuan Education Institute, 14(2), 52-54. 
Hall, Dave (2007). Business ethics and corporate social responsibility. Teaching Business \& Economics, 11(2), 5-7.

Heron, W. T. (2006). An Examination of the Moral Development and Ethical Decision-making of Information Technology Professionals. Doctoral Dissertation, Nova Southeastern University.

Homann, K. (2002). Vorteile und Anreize. ZurGrundlegungeinerEthik der Zukunft.Tu“bingen: Mohr.

Huang, C. (2006). Cross-Cultural Ethics: A Study of Cognitive Moral Development and Moral Maturity of U.S. and Japanese Expatriate Managers in Taiwan and Taiwanese Managers. Doctoral Dissertation, Nova Southeastern University.

Hyppolite, A. A. (2003). The Influence of Organizational Culture, Ethical Views and Practices in Local Government: A Cognitive Moral Development Study. Doctoral Dissertation, Nova Southeastern University.

Kaiser, H. F. (1974). An Index of Factorial Simplicity. Psychometrika, 39(1), 31-36.

Jones, S. K., Hiltebeitel, K. M. (1995). Organizational influence in a model of the moral decision process of accountant. Journal of Business Ethics, 14(6), 417-431.

Kennedy, W. J. (2003). A Study of the Moral Reasoning Skills of Proactive and Reactive Organizational Management. Doctoral Dissertation, Nova Southeastern University.

Mujtaba, B. G., Tajaddini, R., and Chen, L. Y. (August 2011). Perceptions of Ethics by Public and Private Sector Iranians. Asian Journal of Business and Management Sciences, 1(2), 104-118.

Mujtaba, B. G., Afza, T., \& Habib, N. (May 2011). Leadership Tendencies of Pakistanis: Exploring Similarities and Differences based on Age and Gender. Journal of Economics and Behavioral Studies, 2(5), 199-212.

Ram, N., Khoso, I., Jamali, M. B., \& Shaikh, M. F. (2009). Ethical Issues in Private commercial Banks in Pakistan. Australian Journal of Business and Management Research, 1(7), 78-82. 


\section{Author Biography:}

Bahaudin G. Mujtaba, D.B.A., is Professor of Management and Human Resources at Nova Southeastern University's H. Wayne Huizenga School of Business and Entrepreneurship. Bahaudin has served as manager, trainer, and management development specialist in the corporate world as well as a director, department chair and faculty member in academia. His areas of research are ethics, training, and diversity management. Bahaudin can be reached through email at: mujtaba@nova.edu.

Arif Sikander, $\mathrm{PhD}$, is Lecturer of Management at Murdoch University's Business School in Australia. Arif has a local and international experience in aircraft engineering and design, aviation science, entrepreneurship and innovation, strategic technology management, training, lecturing, business planning and H.R.M. He has worked in numerous countries with most of the time spent in Brunei and Australia. He is a highly skilled change facilitator, and has extensive experience in the design, delivery and evaluation of aviation and technology management, strategic management, organization development, transformation and management development programs. His areas of research are technology management, strategic management, strategic human resource management, aviation technology, human factors in aviation and engineering management. Arif can be reached through email at: a.sikander@murdoch.edu.au .

Naveed Akhtar, Ph.D. is Assistant Professor at the Department of Management Sciences at National University of Modern Languages, Islamabad, Pakistan. Naveed Akhtar has served as in Glaxo-Wellcome Pakistan in marketing and sales department for twelve years. He has been teaching MBA \& BBA in Bahria University Islamabad, Pakistan in the department of Management Sciences as visiting faculty member for more than five years. Presently he is full time faculty member of National University of Modern Languages, Islamabad. He teaches "The Learning Organization", and Decision Making and Problem Solving to the Ph.D classes. His areas of research are Organizational Learning, Strategy, and Quality Culture. He can be reached at: naveedakhtarbaloch@yahoo.co.uk

Talat Afza, Ph.D is Professor and Head of Academics and Research at COMSATS Institute of Information Technology, Lahore, Pakistan. She has earlier served as the department chair at the same university and National University of Sciences and Technology Pakistan. Ms. Afza has more than twenty five years of teaching experience including the adjunct professor at University of Michigan, Dearborn and Wayne State University Detroit U.SA. Her areas of research interest include efficiency analysis, Women Entrepreneurships and Business Ethics. She can be reached at: talatafza@ ciitlahore.edu.pk. 